Laboratory and the manufacturers of timber preservatives, the causes of breakdown in timber used in cooling-tower packings. A preservative treatment has been adopted which appears to be effective against the most prevalent form of fungal attack, and very sensitive and accurate methods of analysing boiler feed water for dissolved oxygen and for copper and iron have been worked out. Advantage was taken of the dry summer of 1955 to measure the rate of cooling of selected rivers affected by the discharge of circulating water, and research was also carried out into the measurement and amounts of temperature variations of steam and metal in power-station plant.

The Authority continued to support the work of the Building Research Station on the sintering process by which the fine ash from power stations is converted to aggregate and used in brickmaking. Blending of coals with a chlorine content of 0.5 per cent or more proved successful in further trials, and studies in air pollution have shown that a modern power station has no significant effect on groundlevel pollution in the surrounding district. Research on utilization has also continued to expand, and the Authority, besides its membership of the British Electrical and Allied Industries Research Association, the British Coal Utilization Research Association, the British Hydromechanics Research Association, the British Welding Research Association, the British Non-Ferrous Metals Research Association and the British Iron and Steel Research Association, contributes to the work of the Ministry of Fuel and Power on the development of coal-fired gas turbines, and sponsored specific research in some fourteen universities and university colleges through its Committee on Research in Universities, which examines proposals submitted by the Electricity Supply Research Council.

\section{COMMONWEALTH OF AUSTRALIA SCIENTIFIC AND INDUSTRIAL RESEARCH ORGANIZATION}

\section{REPORT FOR 1954-55}

$\mathrm{N}$ the sixth annual report of the Commonwealth $\mathcal{L}$ of Australia Scientific and Industrial Research Organization for the year ended June 30, 1954, attention was again directed to the difficulties experienced by the Organization in recruiting firstclass scientists. At the beginning of the year there were vacancies for 112 research officers, for which posts the minimum requirement is a good honours degree, and there was a net gain of only three in the year. Recruitment of technical officers, however, was satisfactory. Following increases in research salaries, the seventh annual report* records some improvement in the position up to June 1955, and although the net increase in research staff on the year was only twenty-three there was a considerable improve. ment in recruiting during the last months.

The Australian Atomic Energy Commission has now taken over the work of the Atomic Physics Investigation Unit at the University of Melbourne and also that of the Organization's officers at Har-

* Seventh Annual Report of the Commonwealth Scientiflc and Industrial Research Organization for the year ending 30th June, 1955. Pp. 185. (Canberra : Government Printer, 1956.) 118. well. The Section of Meteorological Physics has been designated a Division, and the administration of the Irrigation Research Stations at Griffith and Merbein has been placed under one direction. A third cooperative industrial research organization, the Australian Wine Research Institute, was established by the Wine Research Act, 1955, and during 1954--55 further research projects were sponsored on a cooperative basis. These include investigations by the Division of Building Research of defects in the decoration of fibrous plaster; by the Division of Industrial Chemistry of the extraction of uranium from unfiltered ore pulps; by the Animal Genetics Section of the breeding of mice sensitive and insensitive to cestrogens given subcutaneously; by the Division of Radiophysics on cloud-seeding ; a study of marine fouling by the Division of Fisheries; and of cheese-making by the Dairy Research Section.

The availability of water supplies is probably the greatest natural limiting factor in the Australian environment, and the seventh annual report directs attention to two developments in the Organization's work bearing on this problem, now reaching the stage of large-scale tests. The detailed study since 1947 of the properties of single clouds by the Division of Radiophysics has demonstrated the important part in atmospheric condensation played by nuclei, and has also indicated how, under appropriate conditions, individual clouds can be made to rain by supplying substitutes when the natural nuclei are absent or ineffective. During the past year the emphasis has shifted to a search for more detailed information on the occurrence and behaviour of natural nuclei and on the investigation, supported by field trials, of methods of artificial seeding by which rainfall might be increased over a relatively wide area.

The preliminary work by the Division of Industrial Chemistry on the use of cetyl alcohol to retard evaporation of water from dams and open reservoirs has been so encouraging that, during the summer of $1954-55$, trials were performed on stretches of water from one to three hundred and twenty acres in area. Both projects hold promise of significant returns in relation to the availability of water supplies.

Several important arrangements were made with universities during the year for the integration of research projects. Certain aspects of the work of the Timber Mechanics Section of the Division of Forest Products will be undertaken in the Engineering School, University of Western Australia, and the high-speed electronic computer constructed in the Division of Radiophysics is being transferred on permanent loan to the Department of Applied Mathematics, University of Melbourne, which will also receive a grant of $£ 3,000$ per annum for the maintenance of a mathematical computing centre. It has also been agreed to link closely pastoral research by the Regional Pastoral Laboratory at Armidale and the University faculty of rural science at New England. The University of Adelaide is providing accommodation for the Clay Mineralogy Section of the Division of Soils until the Division's new building is available. A grant for five years has also been made to the University of Adelaide for the establishment of an Animal Ecology Unit. The Organization has received a gift of 250,000 dollars from the Carnegie Corporation of New York towards the construction of a giant radio-telescope in Australia, for which the Commonwealth Government afterwards offered half the cost. 
Expenditure during the year totalled $£ 5,449,643$ compared with $£ 4,861,873$ in 1953-54. Of this, $£ 554,858$ was spent on plant problems, $£ 533,061$ on animal health and production problems, $\mathfrak{£ 4 3 9 , 8 5 0}$ on industrial chemistry, $£ 429,661$ on the National Standards Laboratory, $£ 275,441$ on radiophysics, $£ 266,812$ on wool textile research, $£ 240,654$ on forest products problems, $£ 179,423$ on food preservation and transport problems, $£ 168,400$ on entomological studies, $£ 147,183$ on fisheries investigations, $£ 57,587$ on mathematical statistics, $£ 119,068$ on building research, $£ 116,626$ on fuel research, $£ 105,692$ on land research and regional survey, $£ 102,108$ on biochemical and general nutrition studies, $£ 161,433$ on soil problems, as well as $£ 91,891$ on soils and problems of irrigation settlements, and $£ 83,117$ on wildlife survey. $£ 71,591$ was allocated to tribophysics, $£ 53,671$ to meteorological physics, $£ 42,615$ to dairy research, $£ 33,237$ to plant fibre research and $£ 27,834$ to genetics.

As in the immediately preceding annual reports, the material is arranged according to subject, rather than according to the Divisions or Sections concerned. Besides a full list of staff and personnel of the Council and Committees, there is an index of papers published during the year, arranged according to sections. The Division of Soils is the central body engaged in soil research in Australia and, besides systematic mapping of Australian soils in broad categories, more detailed classification and mapping of soils in specific areas, applied research into soil fertility and on soil mechanics, undertakes fundamental research on the pedology, chemistry, physics, mineralogy and microbiology of Australian soils. Considerable advances have been made in the study of the mineralogy of both clay and the coarser fractions as a guide to soil classification, the genesis of soil profiles, and as a useful attack on the geochemistry of the soil which may enter into fertility problems. Besides the X-ray studies, emphasis is being placed on the petrographic study of the nonclay fraction, and a now section dealing with clay mineralogy has been set up. The approach to microbiological studies has been broadened with the commencement of work on humus and on the nature and activity of organisms in the rhizophere immediately adjacent to the roots.

As part of a long-term programme of investigations of basic importance to plant introduction work in Australia, studies were begun at Canberra on problems of drought resistance and seasonal dormancy in introduced plants. In connexion with biophysical work at the University of Tasmania, a recording growth meter has been constructed which detects growth of a rapidly elongating root in a fow seconds. Studies during the past year have greatly clarified the understanding of cobalt deficiency of grazing sheep and clarified especially the occasional rapid precipitation of the deficiency syndrome in flocks depastured on incipiently cobalt-deficient terrain. Marked progress was also made in the study of $\mathrm{BHC}$ and DDT dipping fluids for control of cattle tick.

The Division of Tribophysics has shown that at least three mechanisms may operate in the liberation of stored energy in the heating of a deformed metal, and the manner in which the energy associated with these three processes varies with the deformation has been studied for nickel, arsenical copper and pure copper. Analytical and kinetic investigations with selected hydrocarbons show that gaseous oxidation at high temperatures occurs in two successive stages, the first controlled by the accumulation of active intermediates in the gas phase, and by processes at the walls of the reaction vessel, whereas in the second stage, gas phase reactions predominate. In the Division of Physics, a new method for controlling humidity, using a small ionic crystal as detecting element, has been devised, which has given promising results in the automatic measurement of dew-point temperature, in the accurate regulation of humidity in air-conditioned rooms, and as a self-balancing instrument with sensitivity equivalent to $0.01 \mathrm{deg}$. C. in dew-point, and response time of only $0.3 \mathrm{sec}$. The energies of alpha particles from certain natural radioactive substances and the gyromagnetic ratio of the proton have been redetermined, and work continued on the relation between the chemical and physical structure of pure compounds and their dielectric properties. Investigation of a proposed method for navigating long-range aircraft by distance measurement was concluded, but is not being carried further on account of the complexity of the instrumentation and the limit of 1,400 miles on the separation of the stations. Laboratory and road trials established the reliability of two radio-Doppler devices for remote measurement of the speed of road vehicles. Basic studies are being made of the physics of the atmosphere, with the object of attaining a more fundamental understanding of the weather and the processes which control it, and the Division of Radiophysics made several important studies relating to the Sun and galaxy. A detailed study of the southern part of the galaxy is in progress, which, when combined with the results from similar studies in the northern hemisphere, should afford a threedimensional map of the spiral structure of the galaxy. A special interferometer, $1 \mathrm{~km}$. wide, for use on solar disturbances is being constructed, while search has been made for evidence of radio emission from the planet Jupiter. Theoretical work centred on the origin and transmission of electromagnetic waves in an ionized gas.

\section{CHEMICAL ENGINEERING IN THE UNITED STATES}

THE Department of Scientific and Industrial Research, Overseas Technical Report No. 2 (pp. vi + 24. H.M. Stationery Office. 2s.), on "Chemical Engineering in the U.S.A.", is one of a series of surveys on technological subjects which is being made under the ægis of the scientific attache to the British Embassy in Washington. The present report was prepared by Dr. P. H. Calderbank, a member of the staff of the Chemical Research Laboratory, and is based on visits to educational and industrial establishments, and on meetings with representatives of those concerned with the selection, training and employment of chemical engineers in the United States. The report deals with the development of chemical engineering, the progress of which in the United States has been spectacular, the present position in chemical engineering education, and some recent trends in chemical engineering practice.

The older engineering professions have been concerned with the application of certain scientific principles to the building of structures and machines. The creation of the chemical industry required the introduction of a new range of principles, among 